\title{
Evaluation of the Chesapeake Bay Foundation's Conservation Education Programs
}

\author{
MICHAELA ZINT,${ }^{*} \ddagger$ ANITA KRAEMER,$\uparrow$ HEATHER NORTHWAY,${ }^{*}$ AND MIYOUN LIM $*$ \\ *School of Natural Resources \& Environment, Dana Building, 430 E. University, Ann Arbor, MI 48109-1115, U.S.A. \\ †eeEvaluations, 1626 Greenleaf Lane, Charlottesville, VA 22903, U.S.A.
}

\begin{abstract}
We conducted an evaluation of the Chesapeake Bay Foundation's conservation education programs to determine to what extent they promote participants' environmentally responsible behavior and reduce teachers' perceived barriers to teaching about the bay. We assessed outcomes of five youth-and two teacher-education programs through pre-, post-, and retention-tests and mail questionnaires from samples of current and past participants. Based on improvements in characteristics that promote environmentaly responsible behavior, such as perceived knowledge of issues and actions, environmental sensitivity, and-particularly-intention to act, we concluded that the education programs increased some youth' and many teachers' environmentally responsible behavior. We also concluded that the teacher-education programs facilitated teaching about the bay by reducing teachers' constraints. As a result of our evaluation, the Chesapeake Bay Foundation implemented several changes that administrators of similar conservation education programs may also want to consider. These changes include focusing programs to target specific, suitable goals; coordinating programs to provide experiences that build on one another; and conducting periodic evaluations.
\end{abstract}

Evaluación de los Programas de Educación en Conservación de la Fundación Chesapeake Bay

Resumen: Evaluamos los programas de educación en conservación de la Fundación Chesapeake Bay para determinar hasta donde promueven conductas ambientalmente responsables de los participantes y reducen las barreras percibidas por profesores para enseñar sobre la babía. Evaluamos los resultados de cinco programas educativos para jóvenes y dos para profesores por medio de pruebas pre-, post- y de retención y cuestionarios por correo en muestras de participantes actuales y pasados. Con base en mejoras de las características que promueven conductas ambientalmente responsables, tal como el conocimiento percibido de asuntos y acciones, sensibilidad ambiental, y particularmente, intención de actuar, concluimos que los programas de educación incrementaron la conducta ambientalmente responsable de algunos jóvenes y de muchos profesores. También concluimos que los programas de educación para profesores facilitaron la enseñanza sobre la bahía al reducir apremios de los profesores. Como un resultado de nuestra evaluación la Fundación Chesapeake Bay instrumentó varios cambios que quizás también quisieran considerar programas de educación en conservación similares. Estos cambios incluyen orientar programas para alcanzar metas específicas y pertinentes; coordinar programas para proporcionar experiencias que se sirvan de base para otras y llevar a cabo evaluaciones periódicas.

\section{Introduction}

Conservation education seeks to increase individuals' knowledge, change their attitudes, and enhance other

‡email zintmich@umich.edu

Paper submitted December 19, 2000; revised manuscript accepted

October 17, 2001. characteristics to promote environmentally responsible behavior (ERB) (Disinger 1983). Because, similar to conservation programs (Kleiman et al. 2000), few conservation education programs have been evaluated (Jacobson 1999), little is known about the extent to which conservation education can achieve this ERB goal. Moreover, past evaluations of conservation education have focused on knowledge gains and attitude changes rather than improvements in ERB and have other limitations that make 
it difficult to draw conclusions about the effects of conservation education on ERB (Leeming et al. 1993).

We present an evaluation of the Chesapeake Bay Foundation's (CBF) education programs to shed light on the ability of conservation education programs to promote ERB. The CBF offers a variety of outdoor and indoor education programs that have many participants (about 25,000 youth and 1,000 teachers in 1998). In addition, CBF has gone beyond the traditional learning model (knowledge $\rightarrow$ attitude $\rightarrow$ behavior) by striving to influence a greater number of, and more specific, characteristics thought to be more likely to promote ERB (Hungerford \& Volk 1990). Lastly, CBF seeks to improve its programs by learning whether they promote ERB ( particularly among youth) and reducing teachers' perceived barriers to teaching about the bay, questions also of interest to other conservation educators.

\section{Methods}

We evaluated the following CBF education programs: (1) field trips of 1 and 3 days held during the school year that immersed youth aged 11-18 in on-the-water activities such as canoeing, water-testing, and fishing with nets; (2) 2-week field trips held in summer during which "gifted" youth aged 11-18 learned about bay ecology, conservation issues, and the local fishing culture while traveling on tributaries and staying on bay islands; (3) the "Catch of the Bay" module of CBF's curriculum for youth aged 11-14. The CBF educators encouraged teachers to use the module's 11 activities and to complete at least one of three recommended service-learning projects; (4) 2-day workshops teachers attended to receive and learn about the curriculum; (5) a "Schools in Schools" shad-restoration project in which youth aged 11-14 raised juvenile shad in a tank and then released them into a local waterway ( pilot phase of the program); and (6) 5-day field inservices held in the summer for primary and secondary teachers that provided handson opportunities to learn about the bay.

We developed evaluation instruments including pre-, post-, and retention-tests for youth and teachers who participated in programs during 1998, an activity log for 1998 curriculum teachers, and mail surveys for individuals who participated in CBF's education programs before 1998. These instruments were administered to groups of individuals or individuals from simple random samples, surveys, and convenience samples (Cochran 1977) (Table 1). Because we could not randomly assign groups or individuals to treatment and comparison groups, this part of our evaluation consisted of a quasi-experimental design (Cook \& Campbell 1979).

We asked youth and teachers in the 1998 treatment groups to complete a pre-test the day before or at the beginning of $\mathrm{CBF}$ education programs and a post-test the day after or at the end of the programs. Youth received a retention-test about 6 months later (we collected too few responses to report these results) and field inservice teachers about 2 months later. We also administered pre-, post-, and retention-tests to youth comparison groups.

To determine to what extent $\mathrm{CBF}$ education programs changed individuals' ERB, our instruments were designed to assess participants actual and perceived improvements in characteristics associated with ERB, as included in the Hungerford and Volk (1990) behavior model. We decided to focus on these ERB characteristics because (1) CBF education programs focused on influencing these characteristics; (2) Hungerford and Volk (1990) argued that interventions that improve these characteristics promote ERB; and (3) it would have been difficult to directly observe participants' ERB.

Because CBF education programs focus on Chesapeake Bay ecology and conservation issues and on environmentally responsible behavior to protect the bay, we asked CBF education staff to identify and prioritize environmental knowledge and behaviors taught by their programs that are specific to the bay. We then selected the most frequently mentioned topics and behaviors with which to measure the following ERB characteristics.

Each youth pre-, post-, and retention-test had six measures for environmental sensitivity (e.g., How much do you care about. . .), six for knowledge of ecology (e.g., Which is not true about submerged aquatic vegetation?), five for perceived knowledge of issues (How much do you know about. . .), two for personal responsibility (It is my personal responsibility to. . .), five for perceived knowledge of actions (I know how to. . .), five for perceived skill in actions (I have the skill to. . .), one for individual locus of control (By working on my own, I can. .), one for group locus of control (By working with others, I can. . .), and five for intention to act (In the next 6 months, I intend to. . .). The remaining questionnaires had one measure for all or select ERB characteristics to shorten the instrument's length and increase the likelihood of response. The questionnaires mailed to past program participants asked them to rate themselves in the ERB characteristics "before" and "after" taking part in CBF education programs to obtain a measure of perceived change. We asked participants to answer mostly closed-ended questions that had 3- to 6-point Likert response options.

To help ensure the validity and reliability of our ERB characteristic measures, we generally adapted them from past studies (Covitt 1998), resulting in acceptable reliabilities (Nunnally 1978) for the summated scales (Cronbach $\alpha$ range $=0.67-0.91)$, except for the two measures of locus of control (Cronbach $\alpha=0.44$ ). We therefore assessed changes in the single measures of individual and group locus of control.

We assessed teachers' perceived constraints to teaching about the bay by adapting measures used to examine teach- 
Table 1. Details on youth and teacher samples of the evaluation of the Chesapeake Bay Foundation education program.

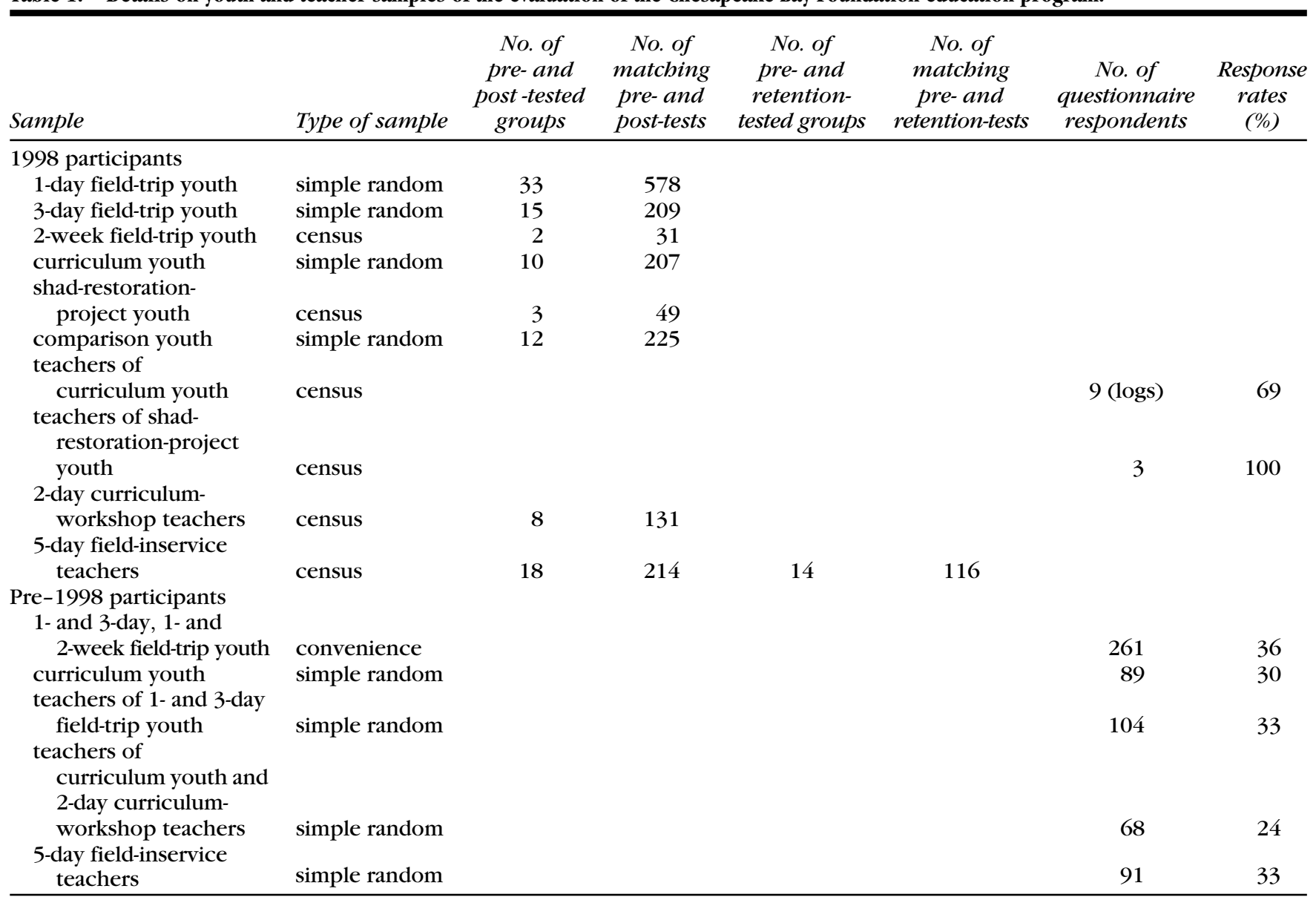

ers' barriers to conservation education in general (Ham \& Sewing 1987-1988; Lane et al. 1994). We developed the teacher activity log based on logs used by other evaluators of conservation education (Iozzi 1996; Hollweg 1997).

Because the youngest evaluation participants were 11 years old, we designed all youth questionnaires for this reading level (Microsoft Word 7.0 Flesch-Kincaid method). We asked experts to review our instruments, pilot-tested the questionnaires, and revised them accordingly.

We used SAS PROC MIXED (Littell et al. 1996) because it is designed for multilevel analysis (i.e., individuals within groups whose responses are not independent) and because it adjusts the dependent variable's (here post-test or afterprogram) mean for fixed-factor effects (here pre-test or before-program, type of treatment, demographic characteristics). We examined results of the test of fixed effects to determine whether fixed factors were significantly related to post-test or after-program ERB characteristics. When we found significant relations, we identified pairwise significant differences in adjusted post-test or afterprogram ERB characteristic means based on the Bonferroni adjustment for multiple comparisons (Sahai \& Ageel 2000). To test for other significant differences when it was not possible or necessary to account for random or fixed effects, we used paired- $t$ and Chi-square tests. We interpreted results as statistically significant at $\alpha=0.05$.

\section{Results}

\section{Effects on 1998 Youth}

We found that 1998 youth scored low to moderate on the nine ERB characteristics before they participated in CBF education programs (Table 2). As suggested by the significant relations between the type of treatment and all nine post-test ERB characteristic means (Table 2), many youth subsequently improved in these characteristics.

Specifically, we found the following significant differences between the treatment groups and the comparison group (Table 2). Youth who participated in 3-day field trips scored higher than comparison youth in all ERB characteristics except intention to act. Two-week field trip youth were higher than comparison youth in all ERB characteristics except personal responsibility and individual locus of control. Participants in 2-week field trips scored high in personal responsibility before partic- 
Table 2. Environmentally responsible behavior (ERB) characteristics of youth participating in 1998 education programs of the Chesapeake Bay Foundation.

\begin{tabular}{|c|c|c|c|c|c|c|c|c|c|c|c|}
\hline \multirow{3}{*}{$\begin{array}{l}\text { Environmentally } \\
\text { responsible behavior } \\
\text { characteristic }\end{array}$} & \multirow{3}{*}{$\begin{array}{c}\text { Range } \\
\text { of } \\
\text { values }^{a}\end{array}$} & \multirow{3}{*}{$\begin{array}{c}\text { Pre-test } \\
\text { mean }\end{array}$} & \multirow{2}{*}{\multicolumn{3}{|c|}{$\begin{array}{l}\text { Test of fixed effects for } \\
\text { type of treatment }\end{array}$}} & \multicolumn{6}{|c|}{$\begin{array}{l}\text { Post-test mean adjusted for pre-test, gender, grade level, and } \\
\text { prior participation in field trips }{ }^{b}\end{array}$} \\
\hline & & & & & & \multirow{2}{*}{$\begin{array}{l}\text { 2-week } \\
\text { field } \\
\text { trip }\end{array}$} & \multirow{2}{*}{$\begin{array}{l}\text { 3-day } \\
\text { field } \\
\text { trip }\end{array}$} & \multirow{2}{*}{$\begin{array}{c}\text { shad- } \\
\text { restoration } \\
\text { project }\end{array}$} & \multirow{2}{*}{$\begin{array}{l}1-d a y \\
\text { field } \\
\text { trip }\end{array}$} & \multirow[b]{2}{*}{ curriculum } & \multirow[b]{2}{*}{ comparison } \\
\hline & & & $\mathrm{F}$ & $d f$ & $\mathrm{p}$ & & & & & & \\
\hline Environmental sensitivity & $6-30$ & 19.94 & 6.72 & $5 / 1138$ & $<0.001$ & $22.66^{c}$ & $21.85^{c} \mathrm{xy}$ & 21.11 & $20.43 x$ & $19.84 y$ & 19.32 \\
\hline Knowledge of ecology & $0-30$ & 12.78 & 5.02 & $5 / 1144$ & $=0.001$ & $19.73^{c}$ & $18.35^{c}$ & 18.45 & $16.39^{c}$ & 16.50 & 12.31 \\
\hline Knowledge of actions & $5-15$ & 9.78 & 9.79 & $5 / 1107$ & $<0.001$ & $12.04^{c} \mathrm{x}$ & $10.97^{c} \mathrm{y}$ & 10.82 & $10.73^{c}$ & $10.01 x y$ & 9.45 \\
\hline Skill in actions & $5-15$ & 9.81 & 7.41 & $5 / 1110$ & $<0.001$ & $11.79^{c} \mathrm{x}$ & $11.09^{c} \mathrm{y}$ & $11.15^{c}$ & $10.72^{c}$ & $10.21 \mathrm{xy}$ & 9.83 \\
\hline \multicolumn{12}{|l|}{ Locus of control } \\
\hline group & $1-5$ & 3.71 & 6.79 & $5 / 1182$ & $<0.001$ & $4.33^{c}$ & $3.99^{c}$ & 3.88 & $3.76^{c}$ & 3.71 & 3.38 \\
\hline individual & $1-5$ & 2.82 & 3.32 & $5 / 1180$ & $=0.005$ & 3.37 & $3.15^{c}$ & 3.18 & 3.03 & 2.90 & 2.85 \\
\hline Intention to act & $5-15$ & 8.40 & 9.04 & $5 / 1185$ & $<0.001$ & $9.61^{c} \mathrm{x}$ & 8.77 & $9.55^{c} \mathrm{y}$ & $9.18^{c} \mathrm{Z}$ & $8.25 x y z$ & 8.28 \\
\hline
\end{tabular}

${ }^{a}$ Higher values reflect greater score on ERB characteristic.

${ }^{b}$ Means within the same ERB characteristic that have the same letter $(x, y$, or $z)$ are significantly different $(\mathrm{p}<0.05)$.

${ }^{c}$ Treatment group's mean is significantly different from no-treatment comparison group mean, $\mathrm{p}<0.05$.

ipating in the program. We believe that this, along with the group's small sample size, explains why these youths' personal responsibility results were not significantly different from that of the comparison group. Participants in 1day field trips scored higher than comparison youth in all ERB characteristics except environmental sensitivity and individual locus of control. Youth participants in the shad-restoration project scored higher than comparison youth in knowledge of issues, skill in actions, and intention to act. Curriculum youth were higher than comparison youth only in knowledge of ecology.

Thus, each of the nine ERB characteristics was affected by at least one of the five programs. All five programs improved youths' knowledge of issues; four improved skill in actions; three improved knowledge of ecology and actions, group locus of control, and intention to act; two improved environmental sensitivity and personal responsibility; and one of the five programs improved youths' individual locus of control.

In terms of significant differences between the five $\mathrm{CBF}$ education programs, we found that participants in the 2-week field trips scored higher than curriculum youth in knowledge of issues, knowledge of actions, skill in actions, and intention to act. Participants in 3-day field trips scored higher in environmental sensitivity than participants in 1-day field trips or curriculum youth, and they scored higher in knowledge of actions and skill in actions than curriculum youth. Participants in the shad-restoration project and the 1-day field trip scored higher than curriculum youth in intention to act.

We believe that we did not find additional significant differences between the five programs because of the relatively small sample sizes of the 2-week field trip and shadrestoration project. Therefore, we conclude that participants on the 2-week field trip scored highest in ERB characteristics, followed by those on the 3-day field trip, on the 1-day field trip, in the shad-restoration project, and, lastly, in the curriculum youth.

Data from teachers' logs provide insight into why curriculum youth may not have performed better. For example, most (67\%) of the curriculum classes experienced only 3 or 4 of the 11 recommended activities, and few (16\%) of the curriculum classes completed a servicelearning project. This level of curriculum use by 1998 teachers was not unusual; only a few (8\%) of the teachers who used the curriculum before 1998 reported using the module in its entirety, and many (40\%) reported that they had not implemented a service-learning project.

\section{Teachers' Assessment of 1998 Youth Effects}

The majority of teachers of the 1998 curriculum and shadrestoration-project youth (we did not ask field-trip teachers) believed that their students improved in almost all of

Table 3. Teachers' opinions of effects on their 1998 students' environmentally responsible behavior (ERB) characteristics.

\begin{tabular}{|c|c|c|}
\hline $\begin{array}{l}\text { Environmentally } \\
\text { responsible bebavior } \\
\text { characteristic }\end{array}$ & $\begin{array}{c}\text { Curriculum }^{a} \\
\text { mean }\end{array}$ & $\begin{array}{l}\text { Sbad-restoration } \\
\text { project mean }^{b}\end{array}$ \\
\hline Environmental sensitivity & 3.17 & 4.00 \\
\hline Knowledge of ecology & 3.33 & 4.33 \\
\hline Knowledge of issues & 3.33 & 4.33 \\
\hline Personal responsibility & 2.83 & 3.67 \\
\hline Knowledge of actions & 3.17 & 4.33 \\
\hline Skill in actions & 2.67 & 4.00 \\
\hline Group locus of control & 3.17 & 4.33 \\
\hline Individual locus of control & 2.33 & 4.00 \\
\hline Intention to act & 2.00 & 4.00 \\
\hline
\end{tabular}

${ }^{a_{\text {Range }}}$ of values 1-4; higher values reflect greater perceived increases.

${ }^{b}$ Range of values 1-5; higher values reflect greater perceived increases. 
the nine ERB characteristics as a result of these two CBF education programs (Table 3). The nine teachers of curriculum youth, however, seemed less confident about improvements in students' ERB characteristics than the three teachers of shad-restoration project youth. For example, the teachers of curriculum youth expected no change in their students' intention to act, whereas the teachers of youth in the shad-restoration project expected increases in this ERB characteristic. Thus, teachers' relative assessments were consistent with students' pre- to post-test results, both with regard to shad-restoration project youth increasing in a greater number of ERB characteristics than curriculum youth, and in terms of the scores on ERB characteristics within the two groups. However, both sets of teachers believed that there were more improvements than we identified. Curriculum teachers expected changes in eight of the nine ERB characteristics, and shad-restoration project teachers expected changes in all nine. We found only one and three changes, respectively. These results suggest that teachers overestimated improvements in their students or that our measures did not adequately capture changes in youths' ERB characteristics.

\section{Effects on Youth in Programs before 1998}

Youth who participated in the programs before 1998 thought they improved in all four measured ERB characteristics as a result of 1- and 3-day, 1- and 2-week, or a combination of CBF field trips (Table 4). Before CBF field trips, these participants rated themselves moderate in these ERB characteristics, and after participating they rated themselves highly.

As suggested by the significant test for fixed-effects results, there were differences between youth (Table 4). Subsequent examinations of pairwise significant differences suggested that participants in 1- and 3 -day field trips scored lower in each of the four ERB characteristics than youth who participated in a combination of field trips. Participants in 1- and 2- week field trips, however, differed significantly from participants in 1-and 3-day field trips only in knowledge of actions, in which they scored higher. Thus, although the means for each group suggested that effects were greatest for the youth participating in a combi- nation of field trips, followed by those participating in 1- and 2-week field trips, and then by those in 1- and 3-day field trips, the middle group did not statistically distinguish itself from the other two groups.

Consistent with respondents' perceived improvements in ERB characteristics, these individuals believed that $\mathrm{CBF}$ education programs changed participants' actions toward the bay. For example, the majority of field-trip participants before 1998 believed that $\mathrm{CBF}$ education programs reached their goal of fostering actions to protect the bay. On a scale from 1 (not at all) to 5 (to a great degree), the mean response of field-trip participants (before 1998) was $4.26(\mathrm{SD}=0.74)$, with no significant difference related to type and combination of CBF field trips. Eighty-two percent of past field-trip participants also reported changing their actions to protect the bay, again with no significant differences based on type and combination of $\mathrm{CBF}$ field trips.

Actions listed most frequently by past field-trip participants included choosing an environmental career, conserving water, recycling, and not littering. Somewhat inconsistent with 1998 intention-to-act results, which indicated no increase for 3-day participants, past participants in 3-day field trips identified more actions per respondent (52 actions mentioned by 51 respondents) than past participants in 1-day field trips ( 54 actions mentioned by 115 respondents).

In contrast, to past field trip participants, significantly fewer past curriculum participants reported changing their actions $\left(80 \%\right.$ versus $71 \%, \chi^{2}=4.29$, df $=1, p=$ $0.038)$. In addition, when asked to give examples of actions, past curriculum participants generally gave statements of awareness and concern instead of actions, as listed by past participants in field trips.

\section{Teachers' Assessment of Effects on Youth in Programs before 1998}

Teachers who took students on 1- and 3-day field trips and used the curriculum with their students in the past believed that youth improved in all four of the measured ERB characteristics. On a scale of 1 (decrease), 2 (no change), 3 (mod-

Table 4. Environmentally responsible behavior (ERB) characteristics of youth who participated in education programs of the Chesapeake Bay Foundation before 1998.

\begin{tabular}{|c|c|c|c|c|c|c|c|}
\hline \multirow{3}{*}{$\begin{array}{l}\text { Environmentally } \\
\text { responsible behavior } \\
\text { characteristic }\end{array}$} & \multirow{3}{*}{$\begin{array}{l}\text { Before- } \\
\text { program } \\
\text { mean }^{*}\end{array}$} & \multirow{2}{*}{\multicolumn{3}{|c|}{$\begin{array}{l}\text { Test of fixed effects } \\
\text { for type of treatment }\end{array}$}} & \multicolumn{3}{|c|}{$\begin{array}{l}\text { After-program mean adjusted for } \\
\text { before-program and level of education* }\end{array}$} \\
\hline & & & & & \multirow{2}{*}{$\begin{array}{l}\text { 1- and 3-day } \\
\text { field trip }\end{array}$} & \multirow{2}{*}{$\begin{array}{l}\text { 1- and 2-week } \\
\quad \text { field trip }\end{array}$} & \multirow{2}{*}{$\begin{array}{l}\text { combination } \\
\text { of field trips }\end{array}$} \\
\hline & & $\mathrm{F}$ & $d f$ & $\mathrm{p}$ & & & \\
\hline Environmental sensitivity & 2.93 & 3.64 & $2 / 250$ & $<0.028$ & 4.22 & 4.24 & 4.53 \\
\hline Knowledge of ecology & 2.45 & 5.55 & $2 / 250$ & $<0.004$ & 4.01 & 4.13 & 4.47 \\
\hline Knowledge of issues & 2.37 & 6.57 & $2 / 250$ & 0.002 & 3.94 & 4.20 & 4.41 \\
\hline
\end{tabular}

${ }^{*}$ Range of values $0-5$; higher values reflect greater score on ERB characteristic. 
erate increase), 4 (great increase), teachers believed their students improved in environmental sensitivity (mean $=$ $3.41, \mathrm{SD}=0.49)$, knowledge of ecology (mean $=3.56$, $\mathrm{SD}=0.51)$, knowledge of issues $($ mean $=3.48, \mathrm{SD}=0.57)$, and knowledge of actions (mean $=3.45, \mathrm{SD}=0.51$ ).

Consistent with teachers' assessments of students' improvements in these ERB characteristics, the majority believed that $\mathrm{CBF}$ education programs reached their goal of fostering actions to protect the bay. On a scale from 1 (not at all) to 5 (to a great degree), teachers' mean response was 4.27 (SD $=0.71)$, and most teachers $(85 \%)$ also believed that CBF's education programs changed their students' actions to protect the bay.

Although there were no statistically significant differences in responses between teachers who had taken their students on field trips and teachers who had used the curriculum, there were differences in the examples of student actions reported by teachers. Teachers of field-trip participants before 1998 frequently identified conserving water and recycling as student actions and listed in-school group projects such as stream clean-ups and wetland plantings. In contrast, teachers of curriculum participants before 1998 generally provided examples of changes in awareness and concern, not of actions as were listed by teachers of field-trip participants before 1998 .

\section{Effects on Curriculum-Workshop Teachers}

For teachers participating in the 1998 curriculum workshops, there were significant differences between preand post-test means for seven of eight ERB characteristics and for 5 of 12 perceived barriers to teaching about the bay, all reflecting improvements (Table 5). After the workshop, teachers were high in ERB characteristics and perceived moderate barriers to teaching about the bay. Because we identified only one significant difference (out of 60 possible) in post-test results based on grade and subject taught and years of professional experience, and because these mean differences were small, we concluded that there were no substantive distinctions in teachers' responses based on these characteristics.

For teachers participating in curriculum workshops before 1998, there were significant differences in all four measured ERB characteristics (Table 5). As reflected by beforeand after-program means, teachers believed they improved and rated themselves high in ERB characteristics after the workshop. Most past participants (70\%) also indicated that as a result of the workshop they had changed their actions to protect the bay. With regard to barriers to teaching about the bay, past participants generally perceived slightly higher barriers than did 1998 participants (Table 5).

Table 5. Effects of curriculum workshops on teachers' environmentally responsible behavior (ERB) characteristics and perceived barriers to teaching about the bay.

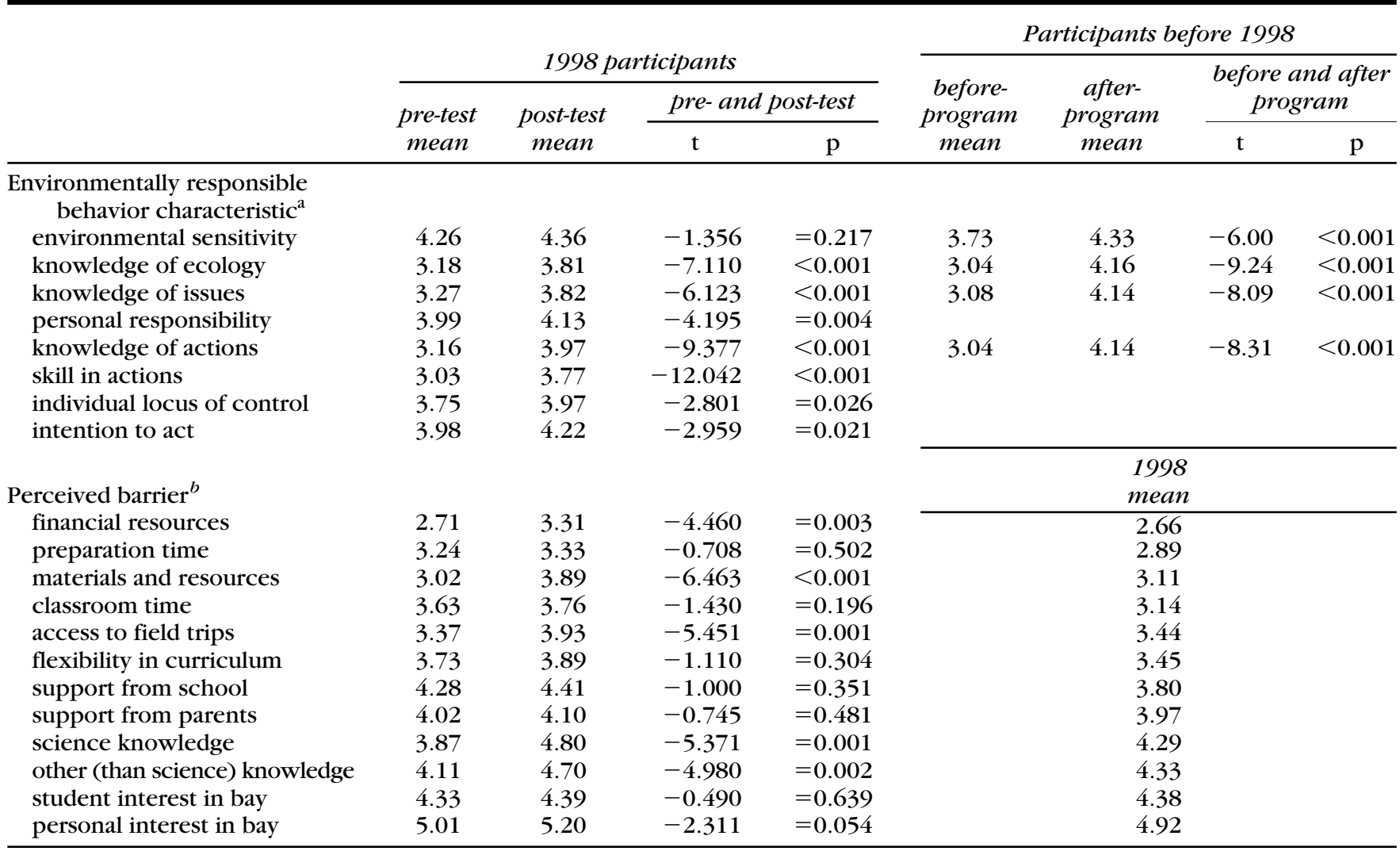

${ }^{a}$ Range 1-5 for 1998 and 1-6 for before 1998; higher values reflect greater score on ERB characteristic

${ }^{b}$ Range 1-6, higher values reflect less of a perceived barrier. 
Table 6. Effects of field inservices on teachers' environmentally responsible behavior (ERB) characteristics and perceived barriers to teaching about the bay.

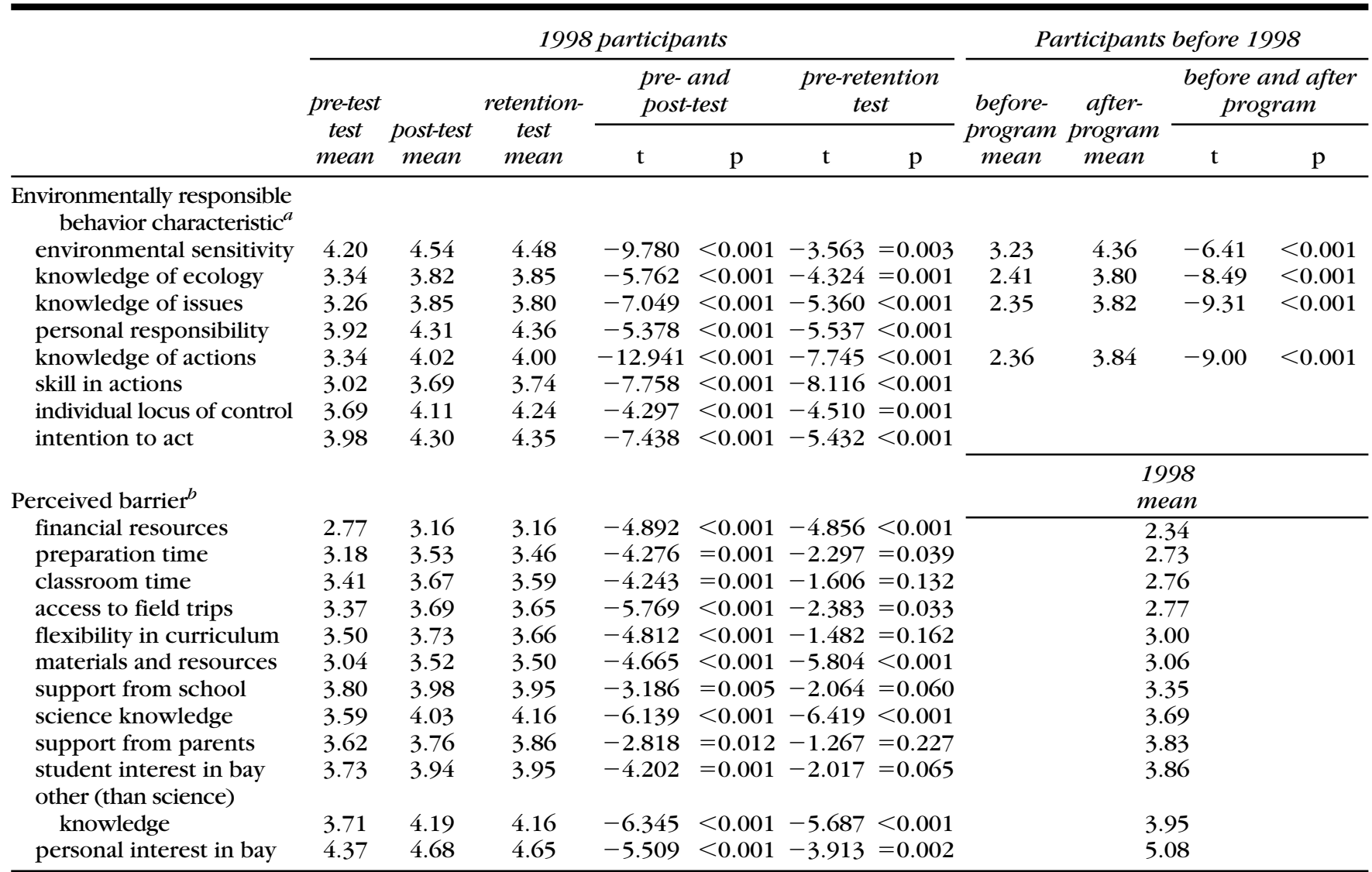

${ }^{a}$ Range 1-5 for 1998 and 1-6 for before 1998; higher values reflect greater score on ERB characteristic.

${ }^{b}$ Range 1-5 for 1998 and 1-6 for before 1998; higher values reflect less of a perceived barrier.

\section{Effects on Field Inservice Teachers}

For 1998 participants in the field inservice, there were significant differences between the group's pre- and posttest means for all eight ERB characteristics and all 12 perceived barriers to teaching about the bay (Table 6). Most of these positive effects remained at least until the retention test administered 2 months later, when inservice teachers were high in ERB characteristics and perceived moderate to low barriers to teaching about the bay. Because we identified only 7 (out of 60 possible) significant differences in retention-test results based on grade and subject taught and years of professional experience, and because these mean differences were small, we concluded that there were no substantive distinctions in teachers' responses based on these characteristics.

For inservice participants before 1998, there were significant differences in all four measured ERB characteristics (Table 6). As reflected by before- and after-program means, teachers believed they improved and rated themselves high in ERB characteristics after the inservice. Most past participants (78\%) also indicated that as a result of the inservice they had changed their actions to protect the bay. With regard to barriers to teaching about the bay, past participants generally perceived slightly higher barriers than did 1998 participants ( Table 6).

\section{Discussion}

To determine to what extent CBF education programs increase participants' environmentally responsible behavior, we relied on assessing participants' improvements in characteristics thought to promote ERB (Hungerford \& Volk 1990). Chesapeake Bay Foundation education programs influenced these characteristics to a range of degrees.

Specifically, we found strong evidence that youth improved in knowledge of issues based on all CBF education programs, environmental sensitivity based on 3-day and 2-week field trips, and knowledge of actions and skill in actions based on all CBF education programs except the curriculum. We also found some evidence that youth improved in knowledge of ecology based on CBF education programs. We had less evidence, however, that youth increased in group locus of control, intention to 
act, personal responsibility, and individual locus of control (in that order), especially based on the curriculum.

Given the time that CBF education programs allocate to providing information about issues, ecology, actions, and group restoration activities, we expected to find improvements in knowledge of issues, ecology, actions, skill in actions, and group locus of control. The improvement of participants in the 3-day and 2-week field trips in environmental sensitivity also was not surprising given that outdoor experiences are predicted to have this effect. With regard to intention to act, we were surprised to find inconsistencies between CBF education programs with respect to the number of ERB characteristics that these programs influenced. For example, participants in the 1998 3-day field trips improved in all ERB characteristics except intention to act, whereas 1998 participants in the shad-restoration project improved in only two other ERB characteristics and intention to act. Findings should have been the opposite: programs that influenced a greater number of ERB characteristics and to a greater extent should have been more likely to increase intention to act. This suggests that further research is needed to the test the Hungerford and Volk (1990) model. Lastly, findings that personal responsibility improved only among participants in 1- and 3-day field trips suggest that this aspect is not stressed sufficiently in other programs. Similarly, findings that individual locus of control improved only among participants in 3-day field trips suggest that the other education programs are not providing enough opportunities for youth to develop self-confidence in their ability to make a difference.

Among individual programs, 1-day field trips performed well in terms of improvements in youths' ERB characteristics, especially considering the short duration of the experience. Three-day field trips also performed well in terms of improvements in a number of ERB characteristics, but given the relative length of their experience, participants in 3-day field trips did not perform as well in terms of ERB characteristic scores. Similarly, participants in 2-week field trips did not appear to be reaching their full potential. This conclusion is based on the number of ERB characteristics affected and scores relative to those of 3-day and 1-day field trips, and on the fact that these students tended to be higher academic achievers. Outcomes of the shad-restoration project were mixed, and it is difficult to reach a conclusion because the program was evaluated during its pilot phase and the sample was small. Curriculum outcomes were disappointing, but not surprising, given that youth did not experience the recommended number of activities and service-learning projects.

With regard to teachers' ERB characteristics, the curriculum workshop and field inservice performed well. With one exception, we observed improvements in all ERB characteristics as a result of these programs. The exception was environmental sensitivity in 1998 curricu- lum-workshop teachers. Given that workshop participants spent most of their time indoors, however, these results are not surprising.

Did CBF education programs increase youths' and teachers' environmentally responsible behavior? We believe it is likely that some youths' and many teachers' ERB increased as a result of participating in CBF outdoor education programs and the curriculum workshop. First, improvements occurred and were perceived to have occurred in the majority of these participants' ERB characteristics. Second, the majority of these participants scored and rated themselves as moderate to high in these ERB characteristics after these programs. Third, the majority of participants reported increases in ERB and gave examples of relevant actions that they or their students engaged in as a result of these programs.

It is the results for intention to act that create some uncertainty about the effects of CBF education programs on youths' ERB. Intention to act is one of the best predictors of behavior, with a mean correlation of about 0.60 (Van den Putte 1991, cited by Eagly \& Chaiken 1993). Our evaluation revealed that 1998 participants in 3-day field trips and the classroom curriculum did not improve in intention to act and that the majority of youths' intention to act was moderate after CBF education programs. In contrast, teachers who participated in CBF education programs improved in intention to act and their intention to act was high, suggesting that teachers were likely to engage in ERB as a result of these programs.

It is unclear to what extent youth in the shad-restoration project increased in ERB. These youth may have increased in ERB because their intention to act increased, but they improved significantly only in three of nine ERB characteristics, with a mix of moderate to high scores. Teachers of these youth also appeared less optimistic about increases in their students' intention to act compared with student improvement in some of the other ERB characteristics.

In light of how teachers implemented it, it is unlikely that youth who participated in the curriculum increased in ERB. These youth improved in only one of nine ERB characteristics, and their scores were moderate. In addition, although many past curriculum youth and their teachers reported changes in actions as a result of learning about the bay, the majority of examples focused on awareness and concern instead of relevant actions. Because most youth experienced only a few of the recommended activities and did not complete a service-learning project, it remains unclear to what extent the curriculum could have increased ERB if implemented as intended.

With regard to effects on teachers, we conclude that many were likely to engage in ERB-specifically, the ERB of instructing their students about the bay. Teachers' intention to teach about the bay was not explicitly assessed, but it was likely to be high in light of their voluntary participation in $\mathrm{CBF}$ education programs. Thus, these teachers would 
have taught their students about the bay unless barriers prevented them from doing so (Ajzen 1985). After participating in $\mathrm{CBF}$ education programs, many teachers' perceived barriers to teaching about the bay were reduced, and only some logistical barriers remained for a few teachers.

\section{Implications}

Changing human behavior is difficult. Considering that CBF education programs, like most conservation education programs, have consisted mostly of short, one-time experiences, our conclusion that these programs have the potential to promote environmentally responsible behavior among some youths and many teachers is encouraging. Our findings also suggest, however, that education programs like CBF's are not meeting their full potential in terms of promoting ERB characteristics and, thus, ERB.

Similar to Gardner and Stern (1996), we believe that education programs need to be focused, provide multiple experiences over extended periods of time, and be coordinated with other interventions to reach their full potential in promoting ERB. Based on these beliefs, we made recommendations that $\mathrm{CBF}$ has implemented and that may also be appropriate for other conservation education programs. For example, rather than attempting to influence all ERB characteristics through each of its programs, CBF is targeting specific, suitable ERB characteristics such as knowledge of ecology through its curriculum and individual locus of control through its 2-week field trips. The $\mathrm{CBF}$ is also increasing its efforts to encourage teachers to coordinate curriculum, field-trip, and restoration activities to provide youth with experiences that build on one another. Lastly, CBF is putting greater emphasis on continuing support for teachers to help them implement the curriculum as intended and further reduce their barriers to teaching about the bay. An evaluation currently underway will determine the effects of these and other changes.

As illustrated by this study, it is challenging to design evaluations that determine the extent to which conservation education programs affect environmentally responsible behavior. Such evaluations are needed, however, to provide insight into the short- and long-term effects of conservation education programs and thus to guide improvements in these programs so that they can make a meaningful contribution to conservation.

\section{Acknowledgments}

The Chesapeake Bay Foundation (CBF) education program, through the Toyota Motor Corporation, funded this evaluation. We would like to acknowledge C. Brecht, S. Bowler, B. Covitt, R. Kaplan, G. Fowler, K. Guire, A. Nettles, and A. Williamson for their assistance with various aspects of this study. We extend special thanks to staff members of the $\mathrm{CBF}$ education program for their ongoing involvement in this evaluation.

\section{Literature Cited}

Ajzen, I. 1985. From intentions to actions: a theory of planned behavior. Pages 11-39 in J. Kuhl and J. Beckmann, editors. Action control: from cognition to behavior. Springer-Verlag, New York.

Cochran, W. G. 1977. Sampling techniques. 3rd edition. Wiley, New York.

Cook, T. D., and D. T. Campbell. 1979. Quasi-experimentation: design and analysis issues for field settings. Rand McNally, Chicago.

Covitt, B. A. 1998. Evaluating an environmental education model for predicting environmentally responsible behavior. M.S. thesis. University of Michigan, Ann Arbor.

Disinger, J. F. 1983. Environmental education's definitional problem. Educational Resources Information Center/Clearinghouse for Science, Mathematics, and Environmental Education, Columbus, Ohio.

Eagly, A. H., and S. Chaiken. 1993. The psychology of attitudes. Harcourt, Brace, Jovanovich, New York.

Gardner, G. T., and P. C. Stern. 1996. Environmental problems and human behavior. Allyn and Bacon, Boston.

Ham, S., and D. Sewing. 1987-1988. Barriers to environmental education. Journal of Environmental Education 19:17-24.

Hollweg, K. S. 1997. Are we making a difference? Lessons learned from VINE program evaluations. North American Association for Environmental Education, Rock Spring, Georgia.

Hungerford, H. R., and T. L. Volk. 1990. Changing learner behavior through environmental education. Journal of Environmental Education 21:8-21.

Iozzi, L. A. 1996. Investigating environmental issues: solid waste for grades 9-12 (evaluation report). Project Learning Tree, Washington, D.C.

Jacobson, S. 1999. Communication skills for conservation professionals. Island Press, Washington, D.C.

Kleiman, D. G., R. P. Reading, B. J. Miller, T. W. Clark, J. M. Scott, J. Robinson, R. L. Wallace, R. J. Cabin, and F. Felleman. 2000. Improving the evaluation of conservation programs. Conservation Biology 14:356-365.

Lane, J. L., R. Wilke, R. Champeau, and D. Sivek. 1994. Environmental education in Wisconsin: a teacher survey. Journal of Environmental Education 45:9-17.

Leeming, F. C., W. O. Dwyer, B. E. Porter, and M. K. Cobern. 1993. Outcome research in environmental education: a critical review. Journal of Environmental Education 24:8-21.

Littell, R. C., G. A. Milliken, W. W. Stroup, and R. D. Woolfinger. 1996. SAS system for mixed models. SAS Institute, Cary, North Carolina.

Nunnally, J. C. 1978. Psychometric theory. 2nd edition. McGraw-Hill, New York.

Sahai, H., and M. I. Ageel. 2000. The analysis of variance: fixed, random and mixed models. Birkhaeuser, Boston.

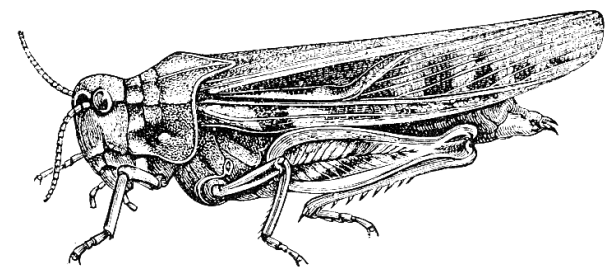

